\title{
Genetic Research on Stored Tissue Samples From Minors: A Systematic Review of the Ethical Literature
}

\author{
Kristien Hens, ${ }^{1 *}$ Herman Nys, ${ }^{1}$ Jean-Jacques Cassiman, ${ }^{2}$ and Kris Dierickx ${ }^{1}$ \\ ${ }^{1}$ Katholieke Universiteit Leuven, Centre for Biomedical Ethics and Law, Leuven, Belgium \\ ${ }^{2}$ Katholieke Universiteit Leuven, Departement Menselijke Erfelijkheid, Leuven, Belgium
}

Received 18 December 2008; Accepted 1 July 2009

The potential benefits of biobank research are well known. Also, the ethical implications of genetic research on stored tissue samples are well discussed in existing literature. The inclusion of tissue samples from minors may have significant scientific value. However, this inclusion raises specific ethical questions. We have performed a systematic search of the literature and found 21 theoretical and empirical articles dealing with the issue. After review, we distilled five clusters of themes: consent, risks, benefits, return of results, and ownership. We have described the different components of these themes, as they occurred in the literature and have provided a discourse on the topic.

(c) 2009 Wiley-Liss, Inc.

Key words: biobank; literature review; minor; genetic research; biological sample; consent; minimal risk; benefit; ethics

\section{INTRODUCTION}

Collections of human biological samples, often called "biobanks," exist in a variety of forms. They can differ in the method of collection, the source of the samples, the aim for which the collection was established, and the type of research. In present-day medical research, genetics play an important role. Although the idea of genetic determinism, which is the belief that genes are solely responsible for physical and psychological traits, is somewhat obsolete, there is a rising interest to know the genes that influence these traits. Collections of stored "raw" tissue (such as blood or bone marrow) or extracted DNA could form an excellent source for genetic epidemiological research, especially if these collections are linked with medical and environmental data.

There is substantial literature on the ethical implications of genetic research using stored tissue samples. Most of this literature focuses on topics such as informed consent, privacy and confidentiality, commercialization and ownership, typically with adult donors in mind [see e.g., Chadwick and Berg, 2001; Deschênes et al., 2001; Godard et al., 2003; Clayton, 2005; Eriksson and Helgesson, 2005; Williams, 2005; Charo, 2006; Roche and Annas, 2006; Petersen, 2007].

Children have long been seen as vulnerable subjects that should be exempt from non-therapeutic research [Pinxten et al., 2008b]. But this exemption can lead to the situation that children become

\section{How to Cite this Article:}

Hens K, Nys H, Cassiman J-J, Dierickx K. 2009. Genetic research on stored tissue samples from minors: A systematic review of the ethical literature.

Am J Med Genet Part A 149A:2346-2358.

"therapeutic orphans": they miss out certain therapies that are only tested on adults, or are prescribed drugs that are never tested in children [Kodish, 2005; Pinxten et al., 2008b]. Nowadays, most guidelines would formulate principles along the lines of those of the Declaration of Helsinki [World Medical Association (WHA) 1964] and allow research on children under certain conditions. In the European Union, The European Directive 2001/20/EC of the European Parliament and of the Council of 4 April 2001 and the implementation by EMEA in its "Ethical considerations for clinical trials on medicinal products conducted with the pediatric population" formulate similar principles [European Medicines Agency EMEA, 2008].

Many biobanks deliberately do not include tissue from children in their collection. This may be due to the fact that storage and use of human tissue in human biobanks has been largely framed in terms of the research subject's rights, with a stress on informed consent [Williams, 2005] But not including children in biobank research poses different challenges. As we have already stated above for research in general, and as pointed out by Williams [2005] for biobanks, this could lead to the situation that genetic research that may result in treatment is not done. Although some argue where genetic research could equally be conducted on adults as on

Grant sponsor: GeneBanC; Grant number: 036751; Grant sponsor: FWO Flanders; Grant number: G029107; Grant sponsor: Eurogentest Network of Excellence of the EU; Grant number: FP-512148.

${ }^{\star}$ Correspondence to:

Kristien Hens, Katholieke Universiteit Leuven, Centre for Biomedical Ethics and Law, Kapucijnenvoer 35/3 Box 7001, 3000 Leuven, Belgium.

E-mail: kristien.hens@med.kuleuven.be

Published online 16 September 2009 in Wiley InterScience

(www.interscience.wiley.com)

DOI 10.1002/ajmg.a.33032 
children [Baumann, 2001], others claim that pediatric genetic research is necessary [Williams, 2005]. For example, scientists now acknowledge the influence of early childhood and prenatal environmental factors on gene expression later in life. To study these factors, it can be argued that data and sample collection for research should start as early as possible. The proliferation of diseases such as allergies, asthma, food intolerances, diabetes, and obesity is attributed to a combination of genetic and environmental factors. To thoroughly understand this interaction, and to develop preventive measures, epidemiological research using genetic databases coupled with environmental and medical data may be appropriate. For more traditional purposes, such as the study of genetic factors of certain childhood cancers, DNA samples from children with that condition could be needed. It would stall research to have to collect these samples and store them until the child has reached the age to consent.

Various child-cohort studies are already being done in different forms. For example, in Bristol the "Avon Longitudinal Study of Parents and Children" ("Children of the nineties") has collected detailed phenotypic and environmental information from pregnancy onwards on approximately 14,000 babies born in 1991-1992 [Pembrey, 2004]. A similar study is "Generation R," which researches growth and health of 10,000 children from Rotterdam, starting from early pregnancy till the children reach adulthood, and "Born in Bradford," which will follow the lives of over 10,000 Bradford babies over the next 20 years. Rasmussen et al. [2002] have described the incorporation of DNA sample collection into the "National Birth Defects Prevention Study" (NBDPS) in the United States. The goal of the NBDPS is the identification of risk factors for birth defects. The biobank of the "Norwegian Mother and Child Cohort Study" (MoBa), holds more than 138,000 biological samples from pregnant women, their parents and their children in storage for over 100 years, thus providing samples for future research studies [Rønningen et al., 2006]. An example of disease-specific use of pediatric tissue is given by Jenkins et al. [2008], who discuss a study to identify genetic and environmental risk factors for certain birth defects. Existing collections of tissue of children are also used. One example is the use of blood spot cards, which are taken from the vast majority of newborns over the Western world. Klotz et al. [2006] describe how these samples can be used for DNA extraction, to study cancer susceptibility genes.

In this paper, we shall review the existing literature on ethical aspects of genetic research using stored tissue from children. We shall distill the main arguments from these papers and provide them in the Results Section. In the Discussion Section, we shall point out the gaps in the literature and provide a starting point for further reflection. We have used the broadest meaning of the term biobank: we have selected articles dealing with longitudinal biobank research, as well as the use of existing archives such as stored blood spot cards.

\section{MATERIALS AND METHODS}

We have searched the following databases: Pubmed, Embase, Cochrane, Web of Science, CINAHL, Psychinfo, Sociological Abstracts, Social Sciences Citation Index, and Philosopher's Index. The following search terms were used: DNA database, stored DNA, archived DNA, DNA collection, biobank, biological sample collection, archived tissue, stored tissue, tissue sample, genetic database, genetic research, child, pediatric, minor, infant, proxy, parental consent, newborn, infant, embryo, preschool, ethics. We have left out articles dealing solely with genetic screening and articles discussing umbilical cord blood banking for transfusion, as well as articles that did not refer to ethical issues. Of the resulting set of articles, the reference list was checked for further relevant information, which resulted in the addition of three book chapters to our corpus. We also checked whether articles that cited the papers found yielded any additional information, which was not the case. Papers up till June 2008 were included.

We did not systematically discuss biobank guidelines, as there are no guidelines that deal with tissue from children alone. An overview of international and national guidelines with regard to this topic can be found in Hens et al. [2009] and Samuël et al. [2008]. The article by Therrell et al. [1996] was included as it appeared in a peerreviewed journal and its content surpasses that of mere guidelines.

Newborns in many countries have a sample of blood taken a few days after birth, for newborn screening for treatable genetic, endocrinologic, metabolic, and hematologic diseases, such as phenylketonuria (PKU) and sickle cell anemia. This blood sample is stored on the so-called "Guthrie cards," filter paper cards containing the blood and some extra information about the infant. These cards are kept for various lengths of time, depending on facility that stores them [McEwen, 1994]. It is possible to extract DNA from these samples [Lysaught et al., 1998]. Hence, blood spot card samples can be considered "inchoate DNA banks [McEwen, 1994]." They form a possibly huge potential resource for genetic research, although they were originally gathered for diagnostic purposes [Klotz et al., 2006]. As they contain de facto material from children, we have included papers that deal with ethical issues in the storage and use of blood spot cards for genetic research. Some confusion may exist regarding the term "children." We have included documents that mention "children" or "minors" and have covered the lifespan from birth till the age of majority. In the text, "children" and "minors" will be used synonymously.

\section{RESULTS}

The result of our search was 20 articles. One is an editorial, 3 are book chapters from edited volumes, and 16 are papers from peerreviewed journals. Of the latter 16, 7 came from medical journals, 6 from ethical and law journals, and 3 from journals dealing with genetics. Four papers contain empirical data with regard to people's opinions on the participation of minors in biobank research, nine papers deal with theoretical-ethical issues regarding this participation. Eight papers deal with ethical and legal issues of the storage and use for further research of blood spot cards gathered for newborn screening.

During our review of these papers, we have distilled five clusters of themes that have special relevance for research on tissue from minors. A theme that is prevalent in the general discussion on research on archived tissue samples, that of commercialization, was left out of the discussion as this was only marginally mentioned by some authors, with no specific bearings on pediatric tissue. The resulting five clusters are consent, risk, benefit, return of results, and 
ownership. We shall now discuss our findings with regard to each cluster separately. We shall first provide theoretical discussions and arguments on each topic, and then add empirical data, if any. In this section, we cite the claims and arguments as they were found in the literature. We shall elaborate on gaps and shortcomings in the Discussion Section.

\section{CONSENT}

The topic most broadly discussed is the one on consent. With regard to consent the following questions arose in the literature. Should consent be sought for further storage or use of pediatric tissue samples? Are parents allowed to consent to storage and use of materials from their children? And if yes, should this consent be supplemented by the assent of the minor? Are parents allowed to consent to any research on the genetic material of their children? Should minors be recontacted to obtain fully informed consent when they reach the legal age of competency? And should they have the right to withdraw from the study?

\section{Consent Requirement}

In literature about biobank research, the need for consent for storage and further use is omnipresent. An issue that is especially linked to blood spot cards, which were originally gathered for newborn screening, is that for most of these cards, no consent for storage or use for research purposes exists. In most countries, such as Canada, USA, and UK, consent for newborn screening is presumed: often no written or oral consent is sought and many parents are unaware that they could refuse screening of their newborn [Laberge et al., 2004]. The nine articles we have found that discuss the storage and further use of blood spot cards agree that newborn screening for treatable disorders without consent can be defended because the benefits to the child are obvious. For example, early detection of PKU and preventive measures can substantially reduce neurological problems in affected babies. However, all authors discussing blood spot cards make a strong distinction between diagnostic use of the samples, for which consent may not be needed as this is considered part of routine care and use for further storage and non-therapeutic research for which consent is needed [Therrell et al., 1996; Lysaught et al., 1998; Elkin and Jones, 2000; Pelias and Markward, 2001; Avard and Knoppers, 2002; Dhanda, 2003; Kharaboyan et al., 2004; Laberge et al., 2004; Thomas, 2005].

\section{Consent by Whom}

The need for consent to storage and subsequent use in nontherapeutic research is not questioned by any author. In the case of tissue samples from legally incompetent minors, this means that consent must be given by proxy. Who should consent for minors who have not the legal capacity to do so? Most authors [Therrell et al., 1996; Lysaught et al., 1998; Elkin and Jones, 2000; Pelias and Markward, 2001; Knoppers et al., 2002; Kharaboyan et al., 2004; Laberge et al., 2004; Helgesson, 2005; Holm, 2005; Thomas, 2005; Burke and Diekema, 2006; Fisher, 2006] acknowledge the fact that biobank storage and research on pediatric samples can be done under a regime of parental consent, where one of the parents or a legal guardian gives consent for the child. Holm [2005] justifies this by stating that the enrollment of children in biobank research in most cases does not have demonstrable negative effects on the children. Only Baumann [2001] suggests that parents or other individuals should not be allowed to consent to the inclusion of their children in such databank, at least until there are sound regulations about genetic discrimination. This author thinks the risks for such discrimination are too high. Moreover, she claims that if inclusion of pediatric samples in a biobank is done nonetheless, both parents should consent. Baumann [2001] gives two arguments: first, she considers DNA sampling to be more than minimal risk, and second, each parent's genetic material is present in the child, so each parent faces equal risk of genetic discrimination. Avard and Knoppers [2002] suggest that the whole family should be involved in the information process, as genetic information affects the family members. These authors do not specify whether this means that all family members should give their explicit consent.

Empirical research by Goodenough et al. [2004] suggests that children seem not to question their parents' decision to enroll them in a longitudinal genetic and environmental study, and most of the children would join again if given the choice. In a study by Neidich et al. [2008], almost half of the women interviewed would be willing to enroll their children in a hypothetical pediatric biobank $(47 \%)$ and $28 \%$ were unsure. Williamson et al. [2004] found that when parents did refuse to consent this was due to their own fears and concerns, and not due to the parents' questioning their right to make such a decision on behalf of their child. Some focus group participants in the study by Kaufman et al. [2008] regard a parent's consent to be sufficient for a minor to participate. On the other hand, some did find pediatric enrollment problematic if consent of participants cannot be obtained, because the child is too young to consent.

Related to the issue of parental consent is the question whether the opinions of the minors matter. These opinions can be expressed through assent (give permission) or dissent (refuse to give permission). Fisher [2006], Avard and Knoppers [2002], Knoppers et al. [2002], Goodenough et al. [2004], Holm [2005], and Helgesson [2005] indicate that older children and adolescents should be asked to assent or dissent. Goodenough et al. [2004] mention the age of 9-11 as the age where children are being used to being offered choices and are gradually making more choices for themselves. Helgesson [2005] states that parents help children to become such autonomous persons by making decisions for them. But to develop autonomy also means being given the capacity to exercise it to the degree one is capable of. Hence information should be given to children according to their age and assent should be sought in addition to parental consent. McHale et al. [2007] describe how, in a UK legal context, the age as of which a minor may autonomously consent may vary depending on whether the consent is for surgery or for storage or further use of the tissue removed. Whether assent should always be sought, or starting from a fixed age, or whether a test for maturity should be used was not discussed in these papers.

Empirical data from Williamson et al. [2004] show that children thought of consent as an ongoing process in relation between themselves and their parents, and that they believed they would 
have more control when they grow older. Also, parents considered the fact that their children were informed during the process as positive. In practice, however, children sometimes felt that they did not have an option to dissent or not to participate with certain activities or assessments in longitudinal research [Goodenough et al., 2004; Williamson et al., 2004].

\section{Scope of Consent}

Another issue is the scope of such proxy consent. First, should a parent be allowed to consent to any study using the genetic material of their child? Second, should the minor be recontacted to obtain fully informed consent once he or she is of legal age to do so? And third, should minors be given the option to withdraw from the study.

A first question is what parents should be allowed to consent to for their children. We found no theoretical discussion on this subject. In the empirical study by Neidich et al. [2008] women who were willing to enroll their child in a pediatric biobank put very few restrictions on the type of research that can be done on samples, with the exception of "cloning."

Secondly, an important question is whether children should be recontacted to give consent when they reach the age where they can legally do so. Burke and Diekema [2006], although admitting that it is costly, are in favor of reconsent because this allows minors to participate more as they grow older, and to gain full consent from them when they reach adulthood. A second argument from Burke and Diekema is that the initial consent was not obtained from the participant him or herself. This second argument is acknowledged by Helgesson [2005] and Fisher [2006] who state that proxy consent and informed consent are fundamentally different: proxy consent does not express the autonomy of the person involved. So, consent should be obtained from participants when they reach the age that they legally can do so. A similar stance is taken by Elkin and Jones [2000] who mention the age of 16 years in a New Zealand context. Also Kaufman's empirical research [Kaufman et al., 2008] describes that people thought children should be recontacted when they became old enough to understand the impact of genetic research or when they turn 18 , hence referring to both maturity and a legal age of majority.

The third aspect of scope of consent is the question to what extent children should have the right to withdraw from the study. No author claimed that children should not be given this right. Elkin and Jones [2000], Pelias and Markward [2001], Kharaboyan et al. [2004], Goodenough et al. [2004], Williamson et al. [2004], Holm [2005], Helgesson [2005], Thomas [2005], and Fisher [2006] stress the importance of the possibility to withdraw. Holm [2005] provides as an argument for this stance: as children have not been able to autonomously consent and give up the right to withdraw at the moment of donation, the right to withdraw for children is more important than the right to withdraw for adult donors. In Kaufman's focus group research [Kaufman et al., 2008], participants also expressed the opinion that children that reach the age of consent or a given level of understanding or maturity should be recontacted and given the possibility to withdraw. There was no further clarification on what this maturity would entail.

\section{RISK}

Which kinds of risk can children encounter when they are enrolled as participants in biobank research? Knoppers et al. [2002], Avard and Knoppers [2002], Williamson et al. [2004], Holm [2005], and Helgesson [2005] refer to the idea that non-therapeutic research on tissue from minors can be performed if there is no more than minimal risk. Empirical data from Neidich et al. [2008] have shown that most women interviewed considered enrollment in a biobank as entailing no more than minimal harm. Three types of harm associated with storage and use of genetic research databases are discussed: physical and emotional harm, breaches of confidentiality, and group stigmatization.

\section{Physical and Emotional Harm}

A first type of risk is physical and emotional harm. With regard to biobanks Kaufman et al. [2008] report that some participants mention that children might experience fear, for example, of needles and the clinical environment, which would erode the trust between parents and child. Participants thought procedures should be minimally invasive and possibly conducted by a physician who is familiar with the child. Some participants thought that children would be overburdened by participation, as they had already a long list of activities. Also, Goodenough et al. [2004] showed that some children said they would not enroll in the research again if they were given the choice as they have already so much to do. Williamson et al. [2004] point out that a parent's view of what is personal information varies from the view of children. They believe that views of children should be respected: what is considered private and vulnerable information changes as the children grow older. Hence, children might feel uncomfortable about certain questions and knowledge which would pose no problems if adults were asked the same things.

\section{Confidentiality}

As the biobanks under discussion also contain genetic information, the risks quoted first and foremost are confidentiality related, such as access by third parties (e.g., insurance companies, employers, the government). This could lead to discrimination of the participants or to personal stigma [Therrell et al., 1996; Elkin and Jones, 2000; Avard and Knoppers, 2002; Dhanda, 2003; Kharaboyan et al., 2004; Holm, 2005; Burke and Diekema, 2006; Kaufman et al., 2008]. Burke and Diekema [2006] and Holm [2005] stress the need for privacy protection. Participants have a right to know how this will be protected. Because DNA-based identification procedures will increase time, participants who enrolled as children have a right to know about privacy protections and risks as adults. Baumann [2001] suggests the risks of biobank research far outweigh the benefits. She is of the opinion that a DNA sample can be used to identify every physical and mental characteristics of an individual and that the potential harm that can occur is genetic discrimination by employers and insurers. In her opinion it is still unsure what DNA will be able to reveal about the individual in the future. Hence, there is a significant possible risk for genetic discrimination associated with genetic biobank research. 
There is also some potential harm when data are accessed by the parents. We shall discuss this when we discuss return of results.

\section{Levels of Identifiability}

Data and samples in biobanks can have different levels of identifiability. Data can be kept completely anonymized, which means there is no way to retrieve the donor's identity with a reasonable amount of effort. They can be kept coded, where the identifying information can be retrieved using one or more keys. Or they can be completely identifiable. Some authors suggest that anonymization appears to remove the risks for privacy breaches [Therrell et al., 1996; Kharaboyan et al., 2004; Laberge et al., 2004]. Others claim that even if the risk for personal harm is minimal after anonymization, the results of genetic research may lead to group stigma, and hence, indirectly may affect the individual [Lysaught et al., 1998; Avard and Knoppers, 2002; Holm, 2005; Thomas, 2005; Burke and Diekema, 2006]. Avard and Knoppers [2002] also prefer anonymization of the sample, but in any case the donor should be informed about the use of anonymized samples. Hence, some suggest that anonymization may be a solution for existing collections, but new donors should be able to decide whether their sample should be kept anonymous or not [Lysaught et al., 1998; Pelias and Markward, 2001; Knoppers et al., 2002; Fisher, 2006].

Williamson et al. [2004] describe how children perceive how their samples are kept: they think their name is on the sample and some children thought the samples would be returned to them after the study. Strikingly, some also thought that these could be used for other things such as police profiles. Parents, on the other hand, did not consider it appropriate that information gathered for one purpose would be used for another purpose.

\section{PERSONAL AND GROUP BENEFIT}

Who should benefit from research on stored tissue samples from minors? Different levels of benefit can be distinguished. First, research may directly benefit the participant. Second, it may benefit others who suffer from the same condition. And third, there may be a benefit to society as a whole. Avard and Knoppers [2002], Knoppers et al. [2002], and Helgesson [2005] refer to general principles of non-therapeutic research on children. They mention that research on samples from minors can only be done if it is not possible to obtain the same results with participants that can consent, and that participants should either benefit directly, or children of the same age, or with the same condition should benefit. In this respect, Holm [2005] states three possible justifications for restricting research to benefits to the same group. First, it acts as an adequate protection, given the historical fact that vulnerable groups have been used in not so ethical research. Secondly, this requirement guarantees that the group of persons with a specific interest and the group of sufferers exist at the same time. However, if research is prospective, or if the group to which a participant belongs is transitory, such as "age," there is a time lag: the sufferers will not directly benefit from research. Thirdly, some people consider all research on children unethical, but admit that this may stall research. They accept the group restrictions out of pragmatic reasons. Holm considers all three justifications as insufficient, and states that it is much easier to justify a complete ban on research on children because they cannot give informed consent than to argument for this particular way of restricting research. This is a route he does not want to take. The requirement that such research should benefit participants directly is difficult to apply to biobank research, as this is typically non-therapeutic. But empirical research from Kaufman et al. [2008] points out that participants believe that regular checkups might increase children's health and that research might lead to more insight in familial genes. Participants of focus groups also recognized benefits to society as a whole. Besides, Goodenough et al. [2004] and Williamson et al. [2004] describe how many children said the purpose of the study they participated in was to help other children. In the Neidich et al. study [2008] however, many women (69\%) believed that the main goal of the research was helping their own child, but $88 \%$ also stated that one of the goals of the research would be to improve scientific knowledge for the benefit of future patients.

\section{RETURN OF RESULTS}

Genetic biobank research is primarily non-therapeutic and in most of the cases there is no direct benefit to participants. But in principle, when data is not kept in an anonymized way, some results could be returned to participants [Kharaboyan et al., 2004; Laberge et al., 2004]. Should results be returned and which ones should be returned? Should only results which may have an immediate benefit for the child be returned, or also results that might be useful at a later time [Lysaught et al., 1998; Ross, 2008]? Avard and Knoppers [2002] and Burke and Diekema [2006] state that the return of results of genetic analysis to parents can trigger anxiety and change the way in which parents treat their children. Burke and Diekema quote the recommendations from the US National Bioethics Committee (NBAC) that state that disclosure needs only occur if results can be used to improve health outcome, hence if there is direct beneficence. If genetic results without immediate medical value are disclosed to parents this is a breach of the autonomy principle, as this prevents the child from exercising the right not to know, a choice a child might make as an adult. Kaufman's empirical data [Kaufman et al., 2008] show that many people thought results should be provided to parents, especially if the child was facing immediate risk. On the other hand, some thought that when findings are inconclusive the return of these findings might do more harm than good. Parents should be given the opportunity to opt out of learning such information. Focus group participants also thought that parents should have access to the data from their children, at least until they reach maturity.

\section{OWNERSHIP}

Who is the owner of pediatric tissue residing in biobanks, and the associated medical data? At least five options exist: the institution where the collection is housed, the state, the researchers, the parents, or the child. With regard to blood spot cards, Lysaught et al. [1998] ask whether the owner is the state or the parents: if we consider the state to be the owner, can parents still express specifications about the disposition of the child's sample? For example, can they decide whether it should be destroyed rather 
than retained, which secondary uses are allowed, should it be anonymized or identifiable? Pelias and Markward [2001] describe three aspects of full ownership: possession (physical dominion), enjoyment (having the benefit of what the thing may yield), and dispensing of the property (the right to sell, donate, or destroy it). The authors state that for historical collections, the full ownership lies with the institutions where the collection is housed. For current and future collections ownership is shared between the institution and the donors: possession lies with the institution or hospital, enjoyment with the donor who may have a right to the information that is generated and with the researcher who can use it for research. The donor also has the right to dispense: to request withdrawal of his or her sample. Elkin and Jones [2000] and Thomas [2005] state that in New Zealand, referring to New Zealand Code of Health and Disability Services Consumers' Rights, blood spot cards are the property of the individual, with the parents acting as surrogate until the child is competent. Williamson et al. [2004] ask whether information about a child, given by the parent, belongs to the child or the parent. She also asks whether there is a difference between information in different ages: does ownership rights change if the information is about a baby's feeding habits or about puberty? Williamson mentions genetic information from placental blood, which can contain DNA information on mother and child. Holm [2005] thinks that disputes with regard to such information should be resolved in favor of the child, because its information is only there through proxy consent. Empirical research from Williamson et al. [2004] shows that children enrolled in the ALSPAC study perceive the tissue belongs to them, although legally they are not the owners. The authors mentioned did not explicitly make a distinction between ownership of tissue and of derived or associated data and information.

\section{DISCUSSION}

We have reviewed 20 papers consisting of legal and ethical literature on stored tissue from minors and results from empirical studies. We distilled five major clusters from these studies: consent, risk, benefit, return of results, and ownership. We shall now provide our own comments on the findings on consent, risk, benefit, and return of result and conclude by pointing out some gaps. We have left out a thorough discussion on ownership, as this is primarily a legal concept and hence is outside of the scope of this article. As some aspects of ownership are also ethically relevant, such as who has decision capacity over the tissue and information stored, we have included it in the analysis, but these aspects are discussed as part of other topics.

\section{Consent}

The majority of issues discussed were related to the issue of consent. All papers agreed that tissue should not be stored and used for research without written consent. This was stressed especially in the papers on blood spot cards: although taking and storing of blood samples of newborns without explicit written consent by the parents was considered acceptable in the context of diagnosis and treatment, it was not deemed acceptable that these would be reused for non-therapeutic genetic research. Minors and especially young children are not deemed legally competent to give fully informed consent. Who should then give consent for the inclusion of the tissue sample of the child? The validity of parents giving such consent is not questioned by most articles. This consent is then proxy consent, rather than an autonomous consent, as the decision was made on behalf of the child.

We can discern three approaches to proxy consent: the theory of substituted judgment, that of best interest, and an approach that stresses parental interest [Ross, 2006; Wrigley, 2007; Nagasawa, 2008]. First, the theory of substituted judgment states that a consent given by proxy aims at best representing what the incompetent patient would decide if he or she were competent. In the context of pediatric consent, substituted judgment is problematic, especially with babies and young children, as they have never been competent and their wishes have not yet known [Nagasawa, 2008]. The theory of best interest states that a decision is made on behalf of the incompetent person in his or her best interest. This is also problematic when applied to biobank research as most of this research has no direct benefit to the participants. What is best interest in non-therapeutic research? According to Ross [2006] parental permission also serves to respect a legitimate parental interest in making decisions for their child: respect for children means respect for people they are becoming. Hence, to allow nontherapeutic research may mean respecting the child's development and hope of the kind of person the parents want the child to become. In this context, parents may be allowed to consent to the enrollment of their children in biobank research, even if this type of consent does not fit into the scheme of substituted judgment or best interest.

Should both parents consent to the enrolment of children in biobank research? As for pediatric participants of non-therapeutic research in general, Ross [2008] suggests that when this research involves more than minimal risk, the consent of two parents may ensure greater protection. On the other hand, she wonders whether this is truly feasible: not only must both parents consider the risks and benefits of the child's participation, but they both must be able and willing to sign for his or her participation. In a society where many families do no longer consist of two parents with their (genetic) children this may be difficult. Does the fact that the research focuses on genetic information, which is shared with both parents, make a difference? In our opinion, consent from both parents should be seen as a best practice, rather than as an absolute requirement. This would correspond to, for example, the implementation of the European Clinical Trial Directive (2001/20/EC) in Belgian law. This law is applicable to clinical trials and states that in principle, parental consent is granted by both parents. However, as this may be difficult to achieve and in practice the consent of the second parent is assumed [Pinxten et al., 2008a].

Most authors we reviewed considered it to be good practice to ask for assent from the child, next to parental consent, when he or she is able to give such assent. The literature did not specify whether this should be done based on a fixed age or on maturity, and if the latter is the case, how this maturity should be assessed. However, there is no consensus or guideline as of which age children should be allowed to assent to non-therapeutic research. For example, Wendler and Shah [2003] suggest a fixed threshold for assent at 14 years of age, but think a dissent requirement should be adopted for all children regardless of age in the context of non-beneficial 
research. On the other hand, Ashcroft et al. [2003] stress maturity and argues that the capacity to assent is dependent on social context and personal experience, and hence such fixed age is not useful. Finally, Alderson [2008] suggests that also very young children can express their opinions, and that these opinions are valuable in themselves. It is unclear how this should be seen in context of biobank research: should we disregard the fear of needles of a 5-year-old and take a sample of her blood anyway, as long as the parents have consented? With regard to genetic research on biobank samples, these decisions should be supported by empirical research on children's knowledge of the benefits and challenges of such research specifically Moreover, there is agreement that a child should be allowed to give consent for further research and storage when he or she reaches the legal age to do so. An overview of legal regulations regarding the position of minors in a health care setting in the EU member states shows that this position varies from country to country: the age and circumstances under which minors are allowed to take health care decisions vary in the different countries [Stultiëns et al., 2007]. For example, in countries such as Cyprus, Greece, and Slovakia, the age of medical majority is the same as the legal age of majority (18 years in these cases). Some countries distinguish between the age of medical majority and that of legal majority: the age of medical majority is 15 years in Denmark and Slovenia, 16 years in Lithuania and Spain, and 14 years in Portugal. The Czech Republic and Estonia do not have a fixed age, but consider this on a case-by-case basis, dependent on age and maturity.

With regard to the scope of consent, most papers do not make a distinction between consent for storage and consent for subsequent genetic research. The nature of biobank research is such that samples are stored for several years, and that the types of research done may be unknown at the time of storage. Hence, people actually consent to different things: storage and further research use [Shickle, 2006]. This may also have legal implications which are not always fully understood [Nys, 2008]. Furthermore, there is the question of the type of research parents should be allowed to consent to. Should they be allowed to consent for any study on the genetic material of their children, or only for specific studies? The former is called broad consent: a subject is asked to agree to any future research that can be done with his or her DNA. In the case of specific consent, this means that the donor is recontacted each time a new type of research is done on his or her material [Artizzu, 2008]. In the case of pediatric biobanks this question becomes more complicated: should the parents be allowed to give broad consent for the use of genetic material of the children? Should they be recontacted or should the children be recontacted? Some suggest [Hansson et al., 2006; Wendler, 2006] that biobank participants should be allowed to give broad informed consent for unknown future research. For pediatric tissue sample storage, however the consent is done by proxy: and the minor participants' ideas of what is good research might differ from what their parents consider so [Holm, 2005]. A solution could be to allow parents to consent to storage of the tissue, and for research on specific genes or conditions that their child suffers from. This would correspond to the Helsinki guidelines on non-therapeutic research on minors, that such research would benefit other children of the same age or condition. When the minor reaches maturity, broad consent for further storage and research use could then be sought. On the other hand, one could argue that biobank research is much less "risky" than, for example, clinical trials, and that in that respect, parents should be allowed to give broad consent for their children, for both storage and research, at least until the child is able to assent or consent. However, given the fact that DNA is stable throughout a lifetime, it may seem unfair for parents to give consent to any genetic research on their children's DNA. Given the fact that such consent is given on behalf of the child, it may be reasonable to postpone the choice for "broad" consent to any future genetic research until the minor reaches the age of majority.

There was a consensus in all papers in our review that discuss withdrawal that minors should be given the option to withdraw from a study for which their parents consented. Again, no fixed age or criterion of maturity was specified. An open question is also what this withdrawal should entail. Does this mean that they do not actively participate in activities surrounding the biobank, such as filling in questionnaires or providing extra medical information? Should the actual sample be destroyed or flagged "do not use?" Fact is that in many cases some results that use the minor's data will already be published at the time of withdrawal. As such, a minor never has the capability of completely undoing his or her parent's decisions.

With regard to biobanks, often the discussion is between adherents of the doctrine of informed consent, who emphasize autonomy, and those who emphasize the duty for solidarity for the public good [Chadwick and Berg, 2001]. Some take the middle ground that solidarity is not possible as long as there is not a feeling of trust from the public [Williams and Schroeder, 2004]. Asking for consent is in this respect not so much an action to stress the participant's autonomy, but a tool to generate trust [Deschênes et al., 2001]. Although some papers reviewed mention the need for trust between researchers, the children and their families, this view on informed consent is not explored in depth with regard to children. However, to ensure support of research, it is imperative that such trust is gained also from the children participating in the research. This has been already pointed out for clinical trials involving children by Pinxten et al. [2008b], but it is also applicable to longitudinal genetic research. A policy of ongoing information provisioning and assent helps to gain the trust from children in specific research and in science in general.

There is agreement amongst the authors studied that consent is needed, and that in the case of minors, this consent can be given by a parent. No author doubted that it is good practice to obtain assent from the child as well. They also did not doubt that upon reaching the age of majority, the donor should be recontacted for consent and should be given the option to withdraw from the study. The criteria of obtaining assent were not extensively discussed: should assent be sought from a certain age or of a certain level of maturity? And does this mean that children that fall below the chosen criterion should be excluded from the study? Another topic that was not explored was the content of the parental consent: should parents be allowed to consent to general genetic research on the genetic data of their children, or only to specific studies? The answer to these questions is linked to the amount of risk that is associated with genetic research, a factor which is in itself still uncertain as we shall see in the next part of our discussion. Also, the relation between 
actively engaging children in decisions about genetic research and the trust they will have in research now and as they grow older needs further investigation.

\section{Risk}

The requirement that non-therapeutic research should pose no more than minimal risk to pediatric participants is mentioned in some of the papers reviewed. This is a great difference with research on competent adults, who are deemed capable of choosing and assessing the risks for themselves. The requirement is often used in the context of clinical trials, where the risks are more tangible. In the reviewed articles, although some types of risks are quoted, it is not made clear to which extent these are minimal. Eriksson and Helgesson [2005] think there is less risk involved in biobank research than in human subject research, as there is no risk of direct physical harm. They describe the following possible harms: Non-physical harm is, for example, information being used to the disadvantage of the person (e.g., by insurance companies, or employers, or paternity information). They also mention group harms, which can be external (the attitudes towards a group may change based on knowledge resulting from biobank research) or internal (loss of self-esteem of certain groups). They also pinpoint moral wrongs: one may violate the autonomy, privacy or personal integrity of participants by storing or using their samples. This moral harm can occur if samples are used for research that the participants would object to or if researchers draw conclusion regarding paternity, or access other private data that individuals wish to keep for themselves. This is also applicable to groups, if they are, for example, systematically excluded from the benefits of research. How do these different harms apply to children? First, Eriksson and Helgesson think that physical risk is minimal. But one could argue that physical harm and the anxiety that results from, for example, taking blood or being put in a hospital environment is greater for children who cannot yet understand the purpose. Also, as is mentioned in some papers, the things that children consider private or sensible information may be different from the view of adults, and may change overtime and constitute a moral harm. Hence, also in pediatric biobank research, it is important to discern sensitive information per age group. Many papers also mention the risks of confidentiality breaches by third parties such as insurers and employers, which are probably equally high for minor participants as they are for adults. But the assessment of what is acceptable risk and what is not remains difficult. As Leikin [1996] points out for epidemiological research in general, the criterion mostly used is whether the risk are greater than those generally encountered by children in everyday life. It is also highly dependent on the situation, the particular child and the age of the child. Hence, it remains a highly problematic criterion to allow inclusion of stored tissue samples from children in biobanks. On the other hand, group stigmatization that results from findings from biobank research will also affect children that are part of this group, and this regardless of whether they contributed to the research or not. In this perspective, the risks originating from biobank research with certain groups are more important than those arising from the participation of specific children. This may act as a warning against biobank research in general, but also as an indication that one should not be overly protective of individual child participants in such research.

There is agreement that non-therapeutic research on children should pose no more than minimal risk. However, there is much uncertainty as to what this would mean in the context of biobanks. First, little knowledge exists about the fears and privacy issues as perceived by children: some authors acknowledge that these issues may be different from those experienced by adults, but it is still unclear how access to their genetic information is felt by children. In the context of biobanks in general, confidentiality breaches by third parties such as insurers and companies are often quoted but it is difficult to assess how real these dangers are. Also, although some papers did discuss the issue of anonymization in general, we did not find a thorough discussion whether samples from children specifically would benefit from further protection through anonymization or coding. We think further study is needed to evaluate the amount of risk associated with biobanks, in general and for children specifically and to assess what would be the correct means to protect children against these risks.

\section{Personal and Group Benefit}

What benefit should arise from the use of pediatric tissue? Some papers have stated that research on children should benefit other children with the same age or condition. However, others, such as Holm [2005] consider this to be too restrictive. Moreover, this seems to make longitudinal cohort studies which study the interaction between genes and environment by following children throughout the process of growing up impossible. Some also mention the requirement that research on children should benefit the participants. This is in many cases not applicable to biobank research, although participants might gain some benefits through regular health checkups. However, some of the empirical research we have studied shows that non-therapeutic research, also enrollment in a biobank, is sometimes confused with clinical practice and/ or a personal health benefit, a phenomenon called "therapeutic misconception." de Vries and van Leeuwen [2008] state that up to $80 \%$ of research subjects makes this mistake. It is imperative that during consent procedures parents, and if possible the children are made aware of the fact that the primary aim of the research is benefit to future generations.

\section{Return of Results}

Should any individual results be returned to participants and if so, which results should be returned? General biobank literature has mentioned that, although most biobanks have a policy of not recontacting participants [Williams and Schroeder, 2004], researchers often feel an obligation to disclose results that they believe are clinically relevant [Clayton, 2005]. Some suggest that information should be sent through a physician [Deschênes et al., 2001]. Bookman et al. [2006] state that genetic test results should be reported to study participants when the associated risk for the disease is significant. But at least the consent form should mention opting out of receiving this information.

The question of return of results was not discussed in much depth with regard to minors. However, some specific questions arise in this context that would need further investigation. Should 

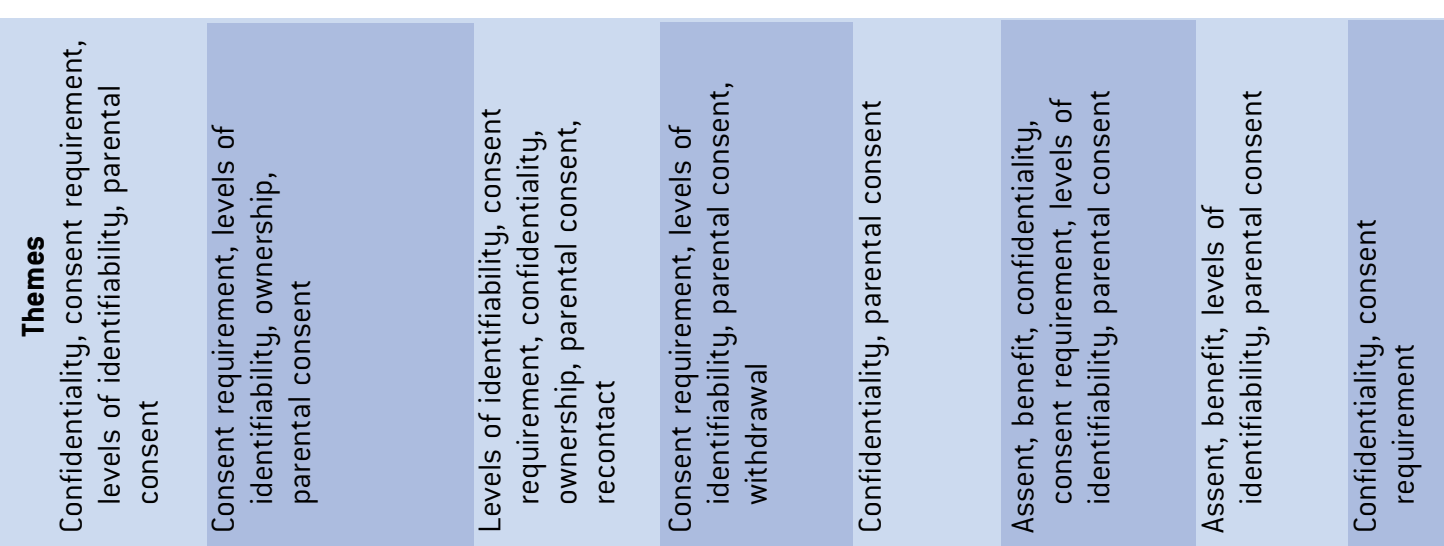

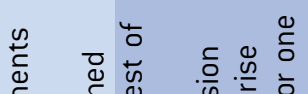

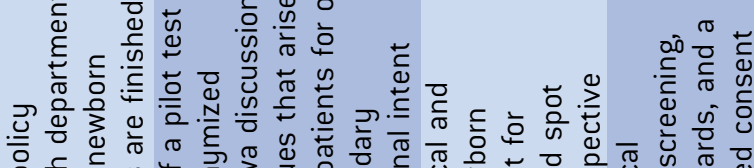

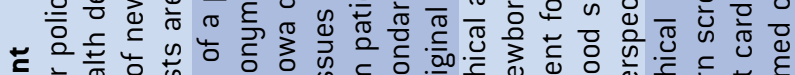

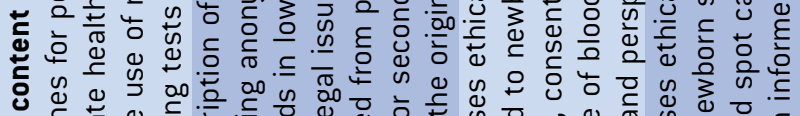

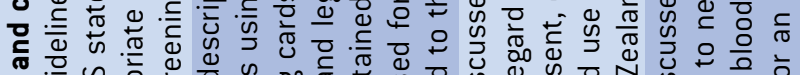

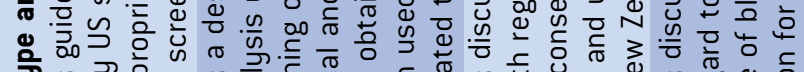
今

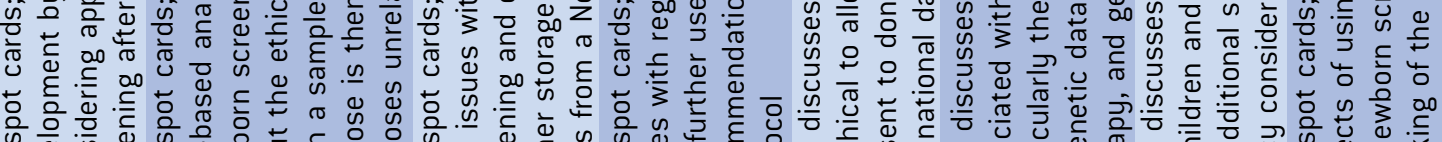

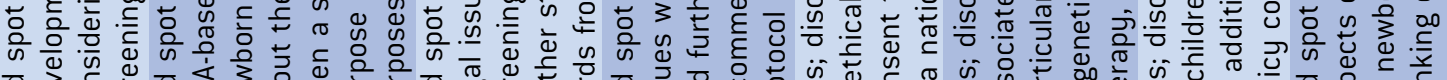
के 응 웡

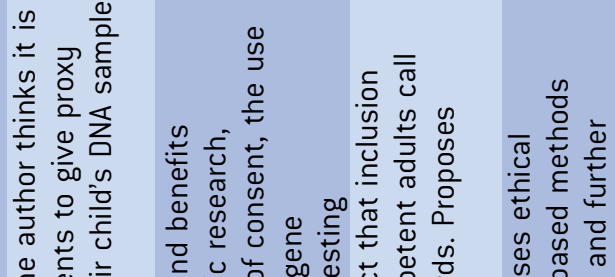

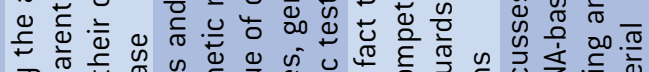
乃 $\frac{0}{2} \frac{\pi}{\pi}$ 舟

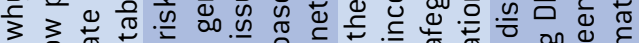

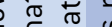

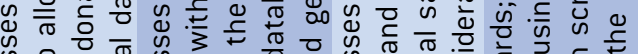
西

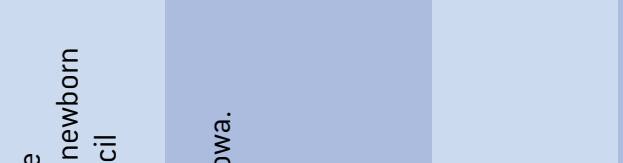

荘

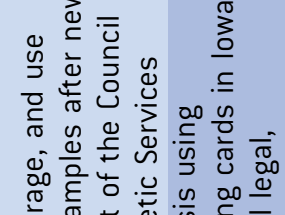

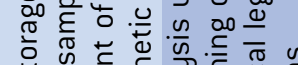

至

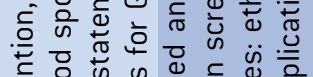

离

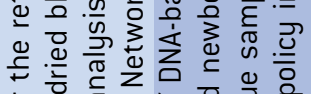

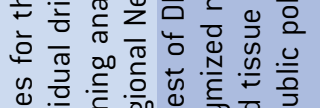

递它

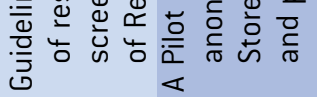

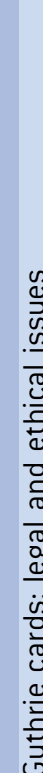

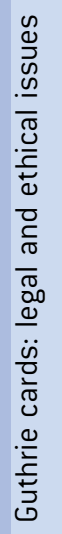

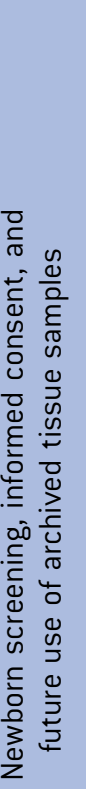

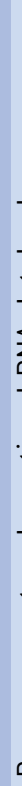
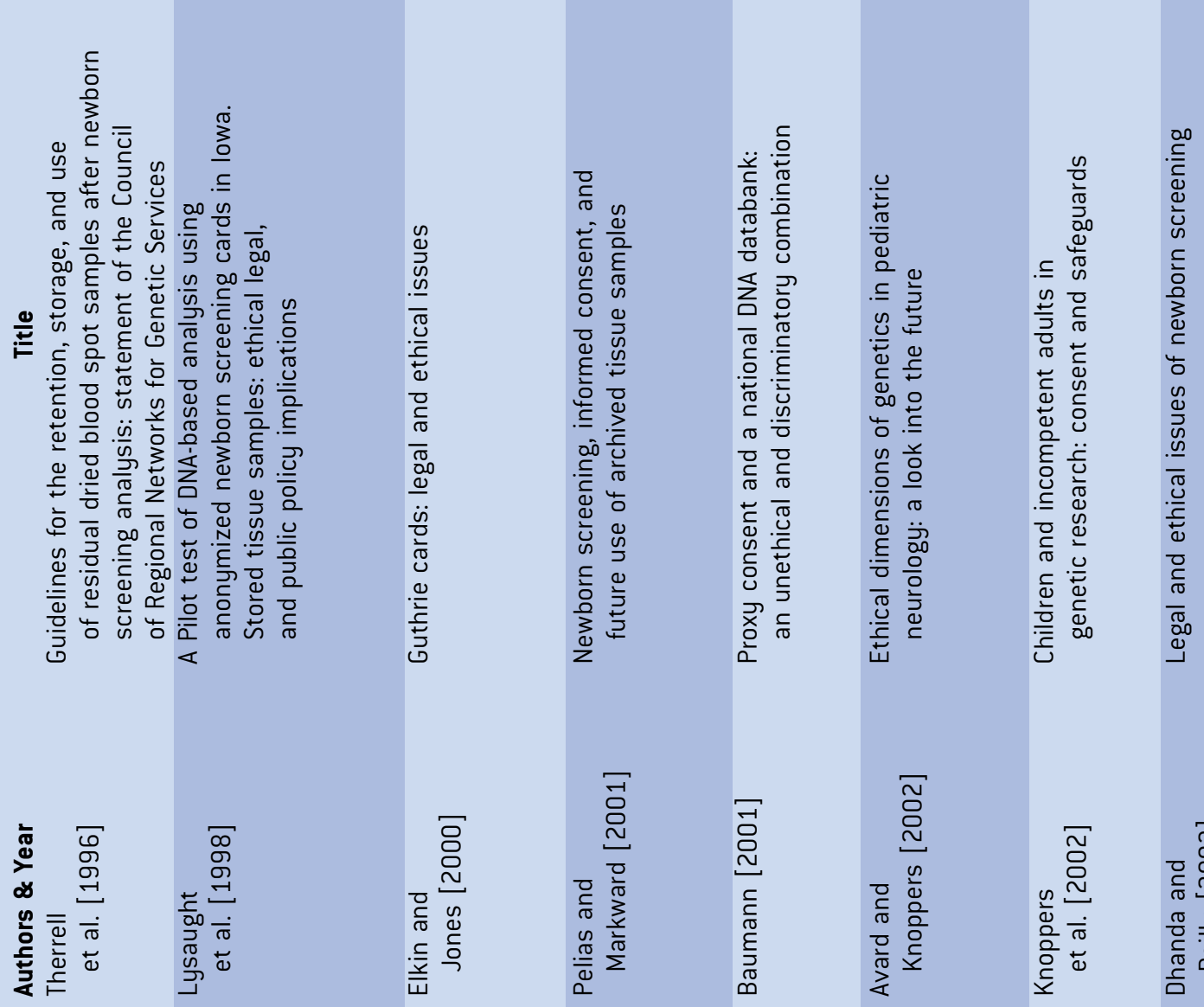

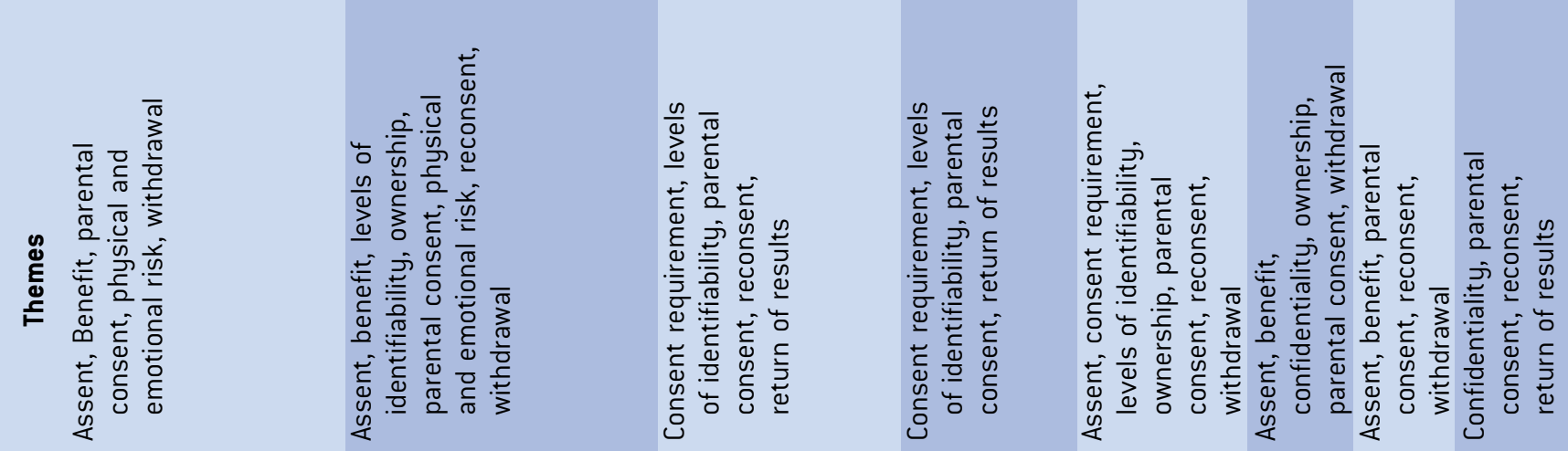

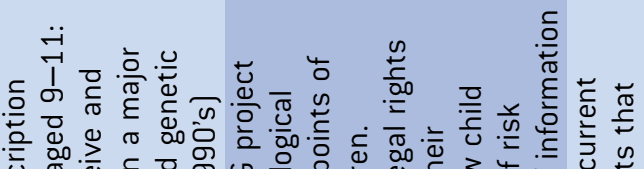

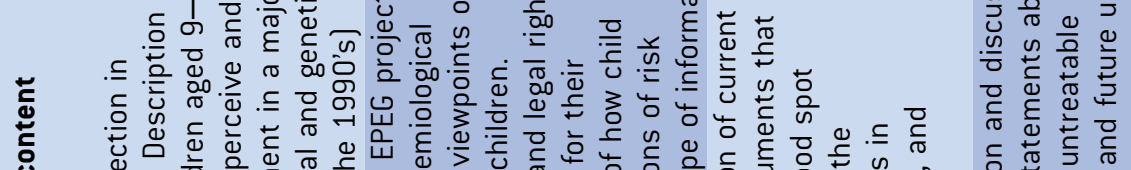

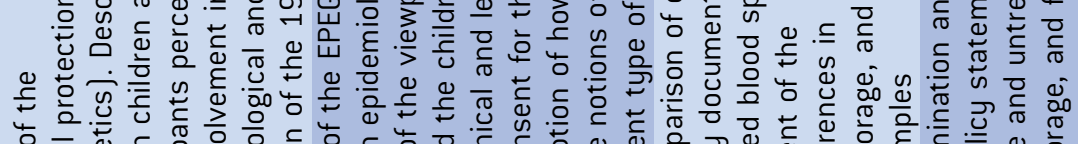

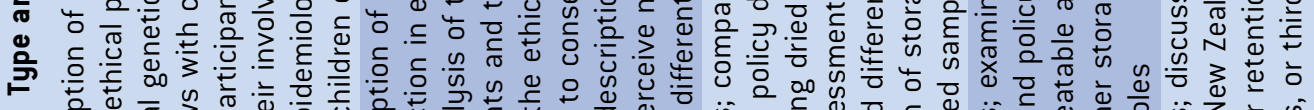

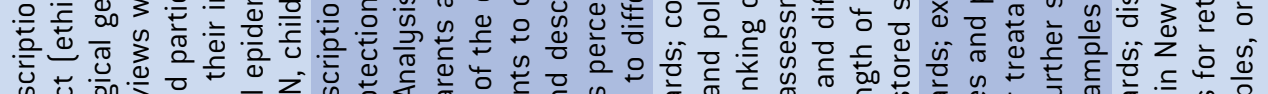

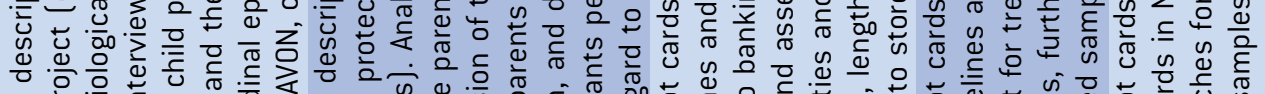

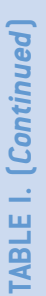

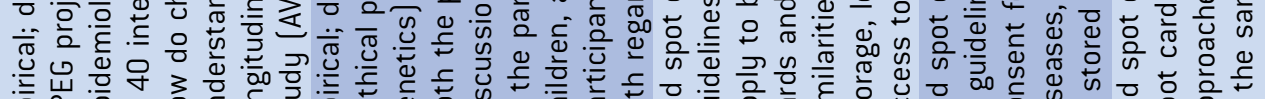

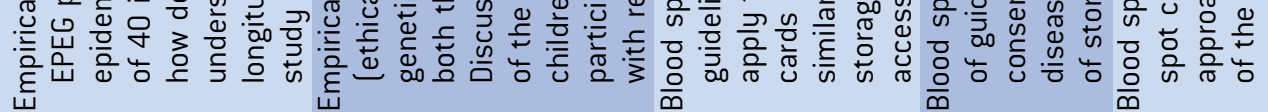
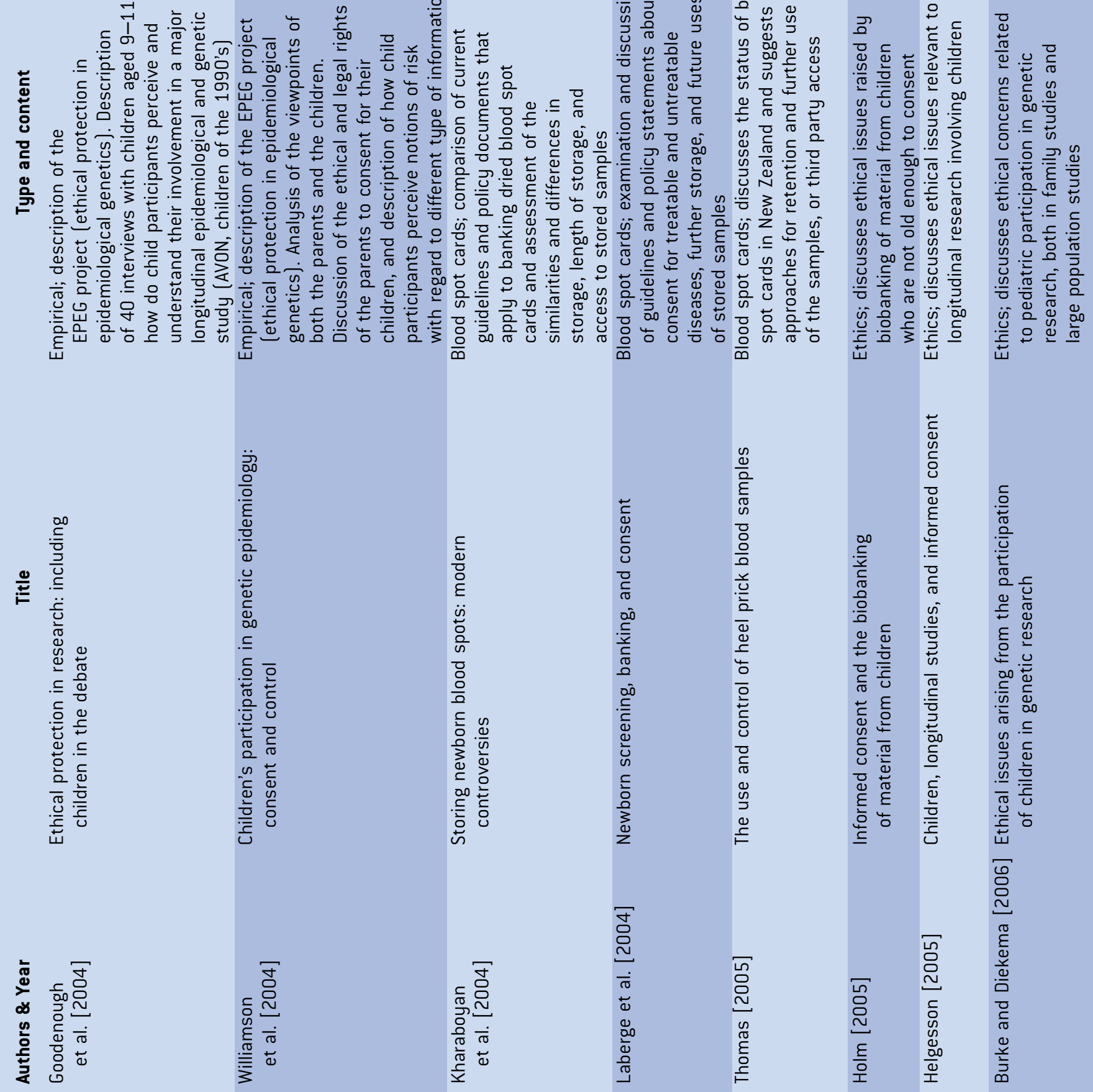


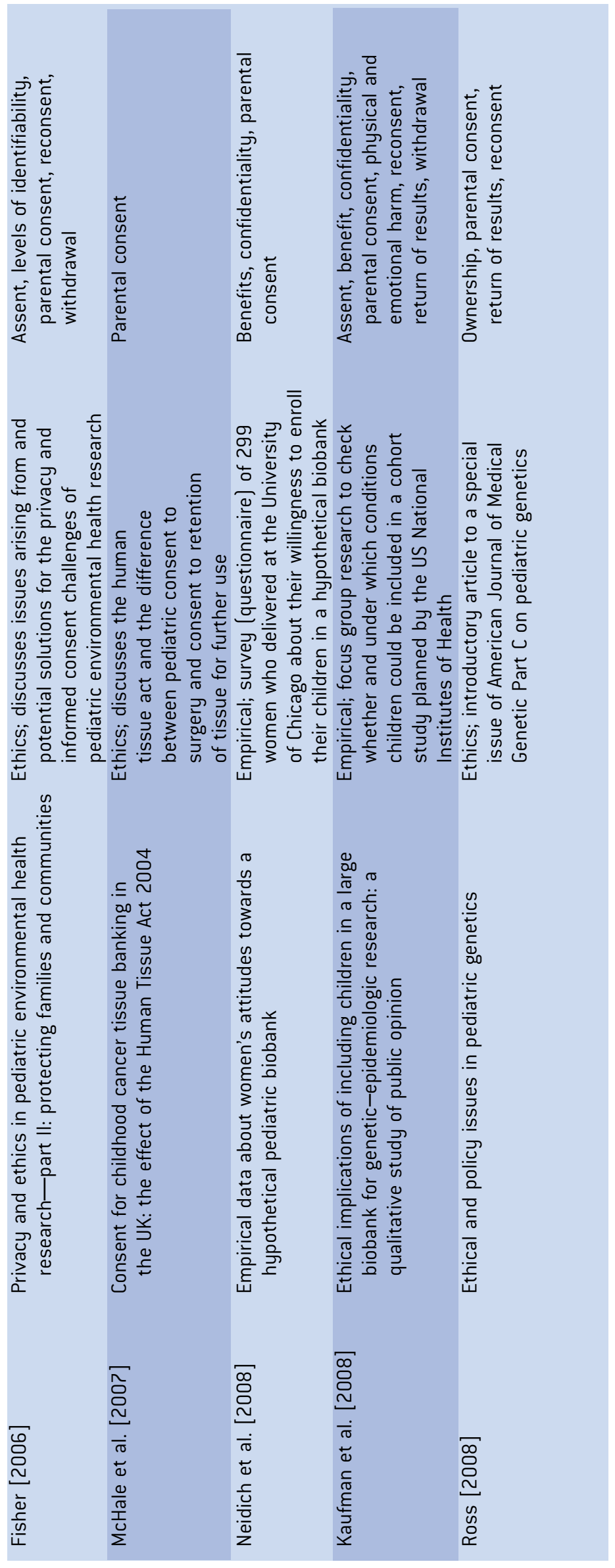

parents be allowed to decide not to receive vital information about their children, or should, in case of a severe and preventable disease, the principle of beneficence take precedence over parental autonomy? And, the other way around, do parents have the right to know details about their children's genetic makeup that are not directly clinically relevant? On the one hand, as genetic information is mostly stable throughout a lifetime, this may put a limit on a parent's right to know. On the other hand, parents are allowed to obtain other information about their children, such as IQ. The major question here is whether genetic information is in any way different from other information, and whether this affects the right parents have to this information on their children. In the literature studied there was no answer to this question.

We have reviewed 20 articles that discuss the ethical issues surrounding the storage and use of pediatric tissue samples from children. From that we have distilled five major themes: consent, risk, benefit, return of results, and ownership. In each of these themes, ethical issues, questions, and answers could be discovered that are different from those involving tissue samples from adults. The fact that we have used such a variety of sources (both theoretical and empirical) could be a limitation of our study. However, some issues were discussed in the empirical literature, where others only came up in more theoretical papers. Another limitation is the fact that we used a broad definition of child, starting from newborn to the age when they reach majority and used all literature that dealt with minors. Ethical issues might be different according to different ages, but given the scarcity of the literature we have opted not discuss these separately, also because in the reviewed literature there was no systematic attention to the different stages of childhood. We also took "biobank research" as broad as possible, and have also included issues related to research surrounding genetic research on tissue, such as phenotypical research using medical data or questionnaires to gather additional information.

Our review of the existing literature on genetic research on stored tissue samples from children has shown that still many questions exist with regard to the conditions under which such storage and research can take place. Indeed, the reviewed articles raise much more questions than that they provide answers. Most of these questions require a more fundamental reflection on the nature of consent, the nature and risks of genetic information, and additional data on the experience of children of such information. Moreover, although both empirical as well as theoretical arguments were found, both types of literature did not seem to inform each other. A thorough examination of the issues at stake, empirical as well as theoretical seems needed. Also, a consideration of the themes based on different age levels is missing, and would be fruitful (Table I).

\section{ACKNOWLEDGMENTS}

This work was supported by GeneBanC, an EU-FP6 supported STREP contract number 036751 and FWO Flanders, project number G029107 and Eurogentest Network of the EU, Number FP-512148.

\section{REFERENCES}

Alderson P. 2008. Young children's rights. London and Philadelphia: Jessica Kingsley Publishers. p 176. 
Artizzu F. 2008. The informed consent aftermath of the genetic revolution. An Italian example of implementation. Med Health Care Philos 11: 181-190.

Ashcroft R, Goodenough T, Williamson E, Kent J. 2003. Children's consent to research participation: Social context and personal experience in validate fixed cutoff rules. Am J Bioeth 3:16-18.

Avard DM, Knoppers BM. 2002. Ethical dimensions of genetics in pediatric neurology: A look into the future. Semin Pediatr Neurol 9:53-61.

Baumann TK. 2001. Proxy consent and a national DNA databank: An unethical and discriminatory combination. Iowa Law Rev 86:667-701.

Bookman EB, Langehorne A, Eckfeldt J, Glass K, Jarvik G, Klag M, Koski G, Motulsky A, Wilfond B, Manolio T, Fabsitz R, Luepker R. 2006. Reporting genetic results in research studies: Summary and recommendations of an NHLBI working group. Am J Med Genet Part A 140A:1033-1040.

Burke W, Diekema DS. 2006. Ethical issues arising from the participation of children in genetic research. J Pediatr 149:34-38.

Chadwick R, Berg K. 2001. Solidarity and equity: New ethical frameworks for genetic databases. Nat Rev Genet 2:318-321.

Charo AR. 2006. Body of research-Ownership and use of human tissue. N Engl J Med 355:1517-1519.

Clayton EW. 2005. Informed consent and biobanks. J Law Med Ethics $33: 15-21$.

de Vries M, van Leeuwen E. 2008. Ethiek van medisch-wetenschappelijk onderzoek: Informed consent en de therapeutische misconceptie. Ned Tijdschr Geneeskd 152:679-683.

Deschênes M, Glass KC, Cardinal G, Knoppers BM. 2001. Human genetic research, DNA banking and consent: A question of 'form'? Clin Genet 59:221-239.

Dhanda K, Reilly PR. 2003. Legal and ethical issues of newborn screening. Pediatr Ann 32:540-546.

Elkin K, Jones D. 2000. Guthrie cards: Legal and ethical issues. N Z Bioeth J $1: 22-26$.

Eriksson S, Helgesson G. 2005. Potential harms, anonymization, and the right to withdraw consent to biobank research. Eur J Hum Genet 13: 1071-1076.

European Medicines Agency (EMEA). 2008. Ethical considerations for clinical trials on medicinal products conducted with the paediatric population. Recommendations of the ad hoc group for the development of implementing guidelines for Directive 2001/20/EC relating to good clinical practice in the conduct of clinical trials on medicinal products for human use.

Fisher CB. 2006. Privacy and ethics in pediatric environmental health research-Part II: Protecting families and communities. Environ Health Perspect 114:1622-1625.

Godard B, Aymé S, Schmidtke J, Cassiman J-J. 2003. Data storage and DNA banking for biomedical research: Informed consent, confidentiality, quality issues, ownership, return of benefits. A professional perspective. Eur J Hum Genet 11:88-122.

Goodenough T, Williamson E, Kent J, Ashcroft R. 2004. Ethical protection in research: Including children in the debate. In: Smyth M, Williamson E, editors. Researchers and their 'subjects'. Bristol: The Policy Press. pp 55-72.

Hansson MG, Dillner J, Bartram CR, Carlson JA, Helgesson G. 2006. Should donors be allowed to give broad consent to future biobank research? Lancet Oncol 7:266-269.

Helgesson G. 2005. Children, longitudinal studies, and informed consent. Med Health Care Philos 8:307.
Hens K, Nys H, Cassiman JJ, Dierickx K. 2009. Biological sample collections from minors for genetic research: A systematic review of guidelines and position papers. Eur J Hum Genet 17:979-990.

Holm S. 2005. Informed consent and the bio-banking of material from children. Genomics Soc Policy 1:16-26.

Jenkins MM, Rasmussen SA, Moore CA, Honein MA. 2008. Ethical issues raised by incorporation of genetics into the National Birth Defects Prevention Study. Am J Med Genet Part C 148C:40-46.

Kaufman D, Geller G, LeRoy L, Murphy J, Scott J, Hudson K. 2008. Ethical implications of including children in a large biobank for geneticepidemiologic research: A qualitative study of public opinion. Am J Med Genet Part C 148C:31-39.

Kharaboyan L, Avard D, Knoppers BM. 2004. Storing newborn blood spots: Modern controversies. J Law Med Ethics 32:741-748.

Klotz J, Bryant P, Wilcox HB, Dillon M, Wolf B, Fagliano J. 2006. Population-based retrieval of newborn dried blood spots for researching paediatric cancer susceptibility genes. Pediatr Perinat Epidemiol 20:449-452.

Knoppers BM, Avard D, Cardinal G, Glass KC. 2002. Science and society: Children and incompetent adults in genetic research: Consent and safeguards. Nat Rev Genet 3:221-225.

Kodish E. 2005. Ethics and research with children: An introduction. In: Kodish E, editor. Ethics and research with children: A casebased approach. Oxford And New York: Oxford University Press. pp 3-25.

Laberge C, Kharaboyan L, Avard D. 2004. Newborn screening, banking, and consent. GenEdit 2:1-15.

Leikin S. 1996. Epidemiological research with children. In: Coughlin SS, Beauchamp TL, editors. Ethics and epidemiology. New York \& Oxford: Oxford University Press. pp 199-218.

Lysaught M, Milhollin L, Peirce R, Getchell J, Rhead W, Susanin J, Anderson J, Murray JC. 1998. A pilot test of DNA-based analysis using anonymized newborn screening cards in Iowa. Stored tissue samples: Ethical, legal, and public policy implications. Iowa City: University of Iowa Press. pp 3-31.

McEwen JE. 1994. Stored Guthrie cards as DNA “banks". Am J Hum Genet 55:196-200.

McHale J, Habiba M, Dixon-Woods M, Cavers D, Heney D, Prichard-Jones K. 2007. Consent for childhood cancer tissue banking in the UK: The effect of the Human Tissue Act 2004. Lancet Oncol 8:266-272.

Nagasawa Y. 2008. Proxy consent and counterfactuals. Bioethics 22:16-24.

Neidich AB, Joseph JW, Ober C, Ross LF. 2008. Empirical data about women's attitudes towards a hypothetical pediatric biobank. Am J Med Genet Part A 146A:297-304.

Nys H. 2008. Research on human biological materials and the Council of Europe: Some unanswered questions, overlaps and empty boxes. Eur J Health Law 15:1-6.

Pelias MK, Markward NJ. 2001. Newborn screening, informed consent, and future use of archived tissue samples. Gen Test 5:179-185.

Pembrey M. 2004. The Avon longitudinal study of parents and children (ALSPAC): A resource for genetic epidemiology. Eur J Endocrinol 151:125-129.

Petersen A. 2007. 'Biobanks' “engagements": Engendering trust or engineering consent? Genomics Soc Policy 3:31-43.

Pinxten W, Dierickx K, Nys H. 2008a. The implementation of Directive 2001/20/EC into Belgian law and the specific provisions on pediatric research. Eur J Health Law 15:1-9. 
Pinxten W, Nys H, Dierickx K. 2008b. Regulating trust in pediatric clinical trials. Med Health Care Philos 11:439-444.

Rasmussen SA, Lammer EJ, Shaw GM, Finnell RH, McGehee RE Jr, Gallagher M, Romitti PA, Murray JC. 2002. Integration of DNA sample collection into a multi-site birth defects case-control study. Teratology 66:177-184.

Roche PA, Annas GJ. 2006. DNA testing, banking, and genetic privacy. N Engl J Med 355:545-546.

Rønningen KS, Paltiel L, Meltzer HM, Nordhagen R, Lie KK, Hovengen R, Haugen M, Nystad W, Magnus P, Hoppin JA. 2006. The biobank of the Norwegian mother and child cohort study: A resource for the next 100 years. Eur J Epidemiol 21:619-625.

Ross LF. 2006. Children in medical research. Oxford and New York: Oxford University Press. p 285.

Ross LF. 2008. Ethical and policy issues in pediatric genetics. Am J Med Genet Part C 148C:1-7.

Samuël J, Ries NM, Malkin D, Knoppers BM. 2008. Biobanks and longitudinal studies: Where are the children? GenEdit 6:1-8.

Shickle D. 2006. The consent problem within DNA biobanks. Stud Hist Philos Sci 37:503-519.

Stultiëns L, Goffin T, Borry P, Dierickx K, Nys H. 2007. Minors and informed consent: A comparative approach. Eur J Health Law 14:2146.
Therrell BL, Hannon WH, Pass KA, Lorey F, Brokopp C, Eckman J, Glass M, Heidenreich R, Kinney S. 1996. Guidelines for the retention, storage, and use of residual dried blood spot samples after newborn screening analysis: Statement of the Council of Regional Networks for Genetic Services. Biochem Mol Med 57:116-124.

Thomas C. 2005. The use and control of heel prick blood samples. Med Law 24:259-277.

Wendler D. 2006. One-time general consent for research on biological samples. Br Med J 332:544-547.

Wendler D, Shah S. 2003. Should children decide whether they are enrolled in nonbeneficial research? Am J Bioeth 3:1-7.

Williams G. 2005. Bioethics and large-scale biobanking: Individualistic ethics and collective projects. Genomics Soc Policy 1:50-65.

Williams G, Schroeder D. 2004. Human genetic banking: Altruism, benefit and consent. New Genet Soc 23:89-103.

Williamson E, Goodenough T, Kent J, Ashcroft R. 2004. Children's participation in genetic epidemiology. In: Tutton R, Corrigan O, editors. Genetic Databases: Socio-ethical issues in the collection and Use of DNA. London and New York: Routledge. pp 139-160.

World Medical Association (WMA). 1964. Declaration of Helsinki. Ethical Principles for Medical Research Involving Human Subjects.

Wrigley A. 2007. Proxy consent: Moral authority misconceived. J Med Ethics 33:527-531. 